\title{
A BIOGRAFIA HUMBOLDT POR ANDREA WULF
}

\author{
Bárbara MESQuita ${ }^{1}$
}

A vida, os métodos de trabalho e a obra publicada do conhecido geógrafo, naturalista e explorador prussiano Alexander von Humboldt (1769-1859) são brilhantemente apresentados nesta biografia intitulada "A Invenção da Natureza - As aventuras de Alexander von Humboldt, o herói esquecido da ciência", da autoria de Andrea Wulf. O título condensa aqueles que são os três objectivos centrais do livro: dar a conhecer a capacidade de Humboldt observar e interpretar as interligações existentes na natureza; relatar a sua vida e viagens, incluindo os métodos de trabalho e as consabidas capacidades de análise e síntese humboldtianas; e, por último, trazer (novamente) a público a relevância do seu trabalho, retirando-o daquilo que a autora considera ser um injusto esquecimento.

De nacionalidade alemã e britânica, e residindo atualmente em Inglaterra, Andrea Wulf é escritora e historiadora formada pelo Royal College of Art de Londres, e tem diversa colaboração assinada em jornais como The Guardian, Sunday Times, Financial Times, LA Times e Wall Street Journal. Entre os livros que publicou anteriormente, destaca-se Chasing Venus. The Race to Measure the Heavens (2012), lançado na ocasião do último trânsito de Vénus, em Junho de 2012. O livro A Invenção da Natureza que tratamos aqui foi já distinguido com diversos prémios, entre os quais se contam Costa Biography Award, Royal Society Science Book Prize, LA Times Book Prize (Science \& Technology), Ness Award "For popularising the histories of geography and of scientific botanical exploration" (Royal Geographical Society) e Bayerischer Buchpreis (Alemanha).

Esta biografia divide-se em cinco partes, assim resumidas: 1) As ideias iniciais e a procura de um destino; 2) a viagem de exploração na América do Sul; 3) o regresso à Europa, a organização e estruturação de toda a informação recolhida durante o périplo americano; 4) a difusão de ideias e a influência do pensamento de Humboldt; 5) os últimos anos de vida e a presença das suas ideias no pensamento ou na ação de autores como o biólogo e filósofo Ernest Haeckel e o naturalista John Muir. No início do livro são apresentados os mapas simplificados das viagens realizadas por Humboldt, sendo feita no final a enumeração exaustiva das suas obras. A presente edição é ilustrada com diversas gravuras a preto e branco, e inclui ainda um caderno central a cores, com imagens ilustrativas da vida e do trabalho do biografado. O texto principal é enriquecido com breves biografias de alguns dos mais destacados interlocutores científicos ou políticos de Humboldt ou de personalidades que foram influenciadas de forma especial pelas suas ideias, como Charles Darwin, Thomas Jefferson ou Simón Bolívar. Darwin foi, aliás, muito inspirado pelas obras de Humboldt: a sua decisão de partir para a

Recebido: fevereiro 2017. Aceite: março 2017.

1 Mestranda em População, Sociedade e Território, Instituto de Geografia e Ordenamento do Território, Universidade de Lisboa (IGOT-Ulisboa), Edificio IGOT, Rua Branca Edmée Marques, 1600-276 Lisboa, Portugal. E-mail: barbara.mar72@gmail.com 
viagem à volta do mundo terá sido determinada pela leitura da "Narrativa Pessoal", onde Humboldt relatou a expedição que realizara à América do Sul.

Alexander von Humboldt nasceu em Berlim, numa família abastada, e teve uma educação intelectual e moral muito sólida. Cresceu em pleno Iluminismo, época que tinha "o progresso como palavra de ordem" e se afirmava confiante em que "ninguém se preocupasse que a própria natureza pudesse ser destruída” (p. 21). Tendo desde cedo demonstrado uma preferência por viagens e temas ligados à natureza, Humboldt foi fortemente influenciado pela filosofia de Kant, pelo que, para si, "o mundo externo, as ideias e os sentimentos fundiam-se uns nos outros" (p. 46).

Graças à fortuna, entretanto herdada, em 1799, Humboldt partiu para a sua grande viagem à América do Sul, acompanhado pelo jovem cientista francês, Aimé Bonpland, e levando consigo uma panóplia de instrumentos científicos. A segunda parte do livro é dedicada a essa viagem de mais de cinco anos pelo continente americano. Salienta-se o carácter apaixonado de Humboldt, e a forma determinada como percorria os locais por onde passava, trabalhando sempre exaustivamente. A autora destaca aqui também a forma como Humboldt "comparava tudo o que via com aquilo que previamente observara e aprendera na Europa" (p. 66), demonstrando, simultaneamente, uma capacidade de observar e analisar em detalhe e a competência excecional para articular os resultados desse trabalho e construir um pensamento integrado sobre os fenómenos observados.

Nessa viagem, Humboldt constatou que a interferência humana na natureza poderia provocar alterações climáticas irreversíveis: "Apenas há algumas décadas, as montanhas e os sopés que rodeavam o vale de Aragua e o Lago Valencia eram florestados. Agora, com as árvores derrubadas, as pesadas chuvas tinham erodido o solo. Tudo estava intimamente ligado, concluía Humboldt” (p. 73). Como o próprio explicitou, "tudo é interação e reciprocidade", afastando-se, assim - remata A. Wulf -, da "perspetiva antropocêntrica que dominara a abordagem da humanidade à natureza durante milénios" (p. 76) e constituindo uma inegável evidência da atualidade do pensamento deste cientista. No mesmo sentido, ao escalar o Chimborazo (Equador), Humboldt teve a ideia de fazer uma representação gráfica da natureza local como uma rede, em que tudo estava ligado. A ideia foi precursora, na medida em que "em vez de pôr as plantas no interior das suas categorias, via a vegetação pelas lentes do clima e da localização: uma ideia radicalmente nova, que continua hoje a moldar a nossa compreensão dos ecossistemas." (p. 118).

Humboldt revelou também claras preocupações humanistas, bastando o exemplo do choque que sentiu ao observar o mercado de escravos de Cumaná (Venezuela) e que o levou a tornar-se abolicionista. É de notar que, contrariamente à maioria dos europeus, Humboldt ficara cativado pelos povos índigenas e referia-se ao "barbarismo do homem civilizado, quando via como o povo local era tratado pelos colonos e pelos missionários” (p. 92). Por outro lado, em Cuba Humboldt registou que grande parte dos solos eram destinados à produção de açúcar, concluindo que tal "era uma receita segura para a dependência e a injustiça”" (p. 137-138) - em boa medida, um pensamento visionário, que associava o colonialismo com a devastação do ambiente e a perpetuação da dependência da metrópole e da injustiça social.

A terceira parte da obra sistematiza a "ordenação das ideias" que Humboldt empreende depois de regressar à Europa, em 1804, e de se ter fixado em Paris, onde rapidamente começou a partilhar os resultados das suas expedições, proferindo conferências, escrevendo várias obras em simultâneo e discutindo com diversos cientistas. Wulf destaca aqui a forma como Humboldt dividia generosamente os espécimes e as informações recolhidos, por acreditar que esta era a forma de fazer avançar a ciência. A publicação em 1805 do "Ensaio sobre a Geografia das Plantas", primeiro volume da monumental "Viagem às Regiões Equatoriais do Novo Continente" marcará este período.

Como referimos, o processo da difusão das ideias de Humboldt no meio científico da época ocupa a quarta parte da obra. Andrea Wulf sublinha aqui o modo como Humboldt se consagrou por inteiro à 
atividade científica e intelectual, e isto apesar do interesse de Frederico Guilherme III lhe ter, entretanto aberto oportunidades de intervenção política em Berlim. Desfrutando de uma impressionante fama pública para um homem de ciência do seu tempo, é sabido que as multidões afluíam às conferências que dava. Em geral, se tratavam de conferências de acesso livre, que muito contribuíram para democratizar a ciência na medida em que incluíam, na assistência, mulheres e pessoas de diferentes condições sociais. Como enfatiza a autora, Humbolt seria muito provavelmente o cientista mais famoso da sua época, na Europa e no mundo.

O livro não podia esquecer a importante viagem exploratória que Humboldt empreendeu em 1829 ao território russo, financiada pelo Czar Nicolau I, com o objetivo de recolher informação sobre metais preciosos. Este contexto não lhe permitiu a liberdade que gostaria de ter tido, quer quanto à escolha do itinerário seguido, quer ao nível da crítica que poderia empreender ao sistema feudal russo.

Em 1834 Humboldt iniciou a redação de uma obra ambiciosa, que visava agregar todo o mundo material: «Cosmo: Um esboço da descrição física do Universo», que viria a ser o seu livro mais influente e cujo primeiro tomo saiu publicado em 1845 (5 e último volume, póstumo, em 1862). Esta obra, que contou com um vasto número de colaboradores, de certa forma corria contra a tendência que se afirmava na época no sentido da "profissionalização das ciências e fortalecimento da separação entre as diferentes disciplinas científicas" (p. 314).

A biografia de Humboldt assinada por Andrea Wulf encerra com o tema "Novos mundos: a evolução das ideias", onde se detalham alguns aspectos da duradoura influência de Humboldt, de que o exemplo mais expressivo será a denominada Corrente de Humboldt. Esta circunstância, não é ainda assim suficiente para conseguir iludir um relativo "esquecimento" do seu multifacetado contributo para a ciência. Wulf considera que este poderá, em parte, dever-se ao facto de Humboldt ter sido um dos últimos grandes polígrafos, numa época que, como referimos, afirmou a divisão entre disciplinas, não valorizando, consequentemente, abordagens holísticas. Por outro lado, a grande herança que deixou corresponde a uma visão integrada da natureza, e não uma descoberta científica concreta, o que também dificultará uma apreensão mais imediata do seu contributo. A estas interpretações juntam-se os sentimentos anti-germânicos generalizados nos períodos posteriores às duas Guerras Mundiais e que Andrea Wulf considera adversos, à partida, ao reconhecimento de um cientista alemão, independentemente deste ter tido a dimensão que Humboldt conseguiu.

Trata-se de uma biografia monumental, que cumpre na perfeição o objetivo de relembrar os contributos de Alexander von Humboldt para a ciência. É um trabalho de investigação muito rigoroso, tendo a autora percorrido arquivos do mundo inteiro e realizado uma parte da viagem de Humboldt à América do Sul. Os contextos sociais e políticos da época são descritos com detalhe, o que facilita a compreensão do texto.

Sendo uma obra de divulgação geral, tem a vantagem acrescida de ter sido redigida num estilo simples e atrativo. Estamos diante de uma leitura muito útil para introduzir as ciências em geral, assumindo uma relevância particular no caso da Geografia. Este interesse deriva, sobretudo, da abordagem holística de Humboldt, que encarava o mundo físico como um todo, visualizando a rede de relações nele existente. Por outro lado Humboldt foi um dos primeiros cientistas a observar e interpretar a influência humana nas alterações do clima, o que o livro também claramente sublinha. Conclui-se com uma frase da obra, que servirá de estímulo à sua leitura: "Os livros, os diários e as cartas de Humboldt revelam um visionário, um pensador muito para lá do seu tempo. Inventou as linhas isotérmicas (...) descobriu o equador magnético. Surgiu com a ideia da vegetação e das zonas climáticas que serpenteiam em torno do globo. O que é mais importante, porém, é que Humboldt revolucionou a forma como vemos o mundo natural. Por todo o lado descobriu ligações. (...) inventou a rede da vida, o conceito de natureza tal como hoje o conhecemos" (p. 6). 


\section{REFERÊNCIAS BIBLIOGRÁFICAS}

Wulf, A. (2016). A Invenção da Natureza - As aventuras de Alexander von Humboldt, o herói esquecido da ciência [The invention of nature - the adventures of Alexander von Humboldt]. Tradução de Pedro Vidal. Lisboa: Temas e Debates.

Recensão realizada no âmbito da unidade curricular Teoria e Métodos da Geografia, Mestrado em População, Sociedade e Território, Instituto de Geografia e Ordenamento do Território, Universidade de Lisboa (IGOT-ULisboa). 